\title{
Gene Flow and Sexual Reproduction in the Wheat Glume Blotch Pathogen Phaeosphaeria nodorum (Anamorph Stagonospora nodorum)
}

\author{
S. M. Keller, J. M. McDermott, R. E. Pettway, M. S. Wolfe, and B. A. McDonald
}

First, third, and fifth authors: Department of Plant Pathology and Microbiology, Texas A\&M University, College Station 77845-2132; second author: TerraGen Diversity Inc., Suite 300, 2386 East Mall, University of British Columbia, Vancouver, BC V6T 1Z3 Canada; and fourth author: Institute for Plant Sciences, Phytopathology Group, Federal Institute of Technology, Zurich, Switzerland. Accepted for publication 19 November 1996.

\begin{abstract}
Keller, S. M., McDermott, J. M., Pettway, R. E., Wolfe, M. S., and McDonald, B. A. 1997. Gene flow and sexual reproduction in the wheat glume blotch pathogen Phaeosphaeria nodorum (anamorph Stagonospora nodorum). Phytopathology 87:353-358.

Restriction fragment length polymorphisms (RFLPs) were used to characterize the genetic structures of three field populations of Phaeosphaeria nodorum from Texas, Oregon, and Switzerland. Data from seven nuclear RFLP loci were used to estimate gene diversity and genetic distances and to make indirect measures of gene flow between populations. Three of the seven RFLP loci differed significantly in allele frequencies

vision, suggesting that gene flow was not restricted among populations. Based on an average population differentiation of 0.04 , we estimated that the exchange of 11 migrants among populations per generation would be needed to account for the present level of population subdivision. Genotype diversity based on DNA fingerprints was at a maximum for the Swiss population, whereas populations in Texas and Oregon had lower genotype diversities. Many multilocus haplotypes were found in each population. Ninety-five percent of RFLP allele pairs were in gametic equilibrium. The data were consistent with random mating within each population.
\end{abstract} across populations. On average, $96 \%$ of the total gene diversity was found within populations. There was little evidence for population subdi-
Additional keywords: population genetics, Septoria nodorum.
Phaeosphaeria nodorum (E. Müller) Hedjaroude ( = Leptosphaeria nodorum E. Müller, anamorph Stagonospora nodorum (Berk.) Castellani \& E.G. Germano, = Septoria nodorum (Berk.) Berk. in Berk. \& Broome) causes Septoria glume blotch on wheat (Triticum aestivum L.). Previous studies indicate that three issues are of major interest in this plant pathosystem: (i) the geographical distribution of neutral and selected genes $(10,21)$, (ii) the adaptation of isolates to specific host varieties $(1,18)$, and (iii) the source of the primary inoculum that starts the epidemic $(7,22)$. These topics are of interest because of the need to develop better strategies for disease management. Early studies of genetic variation that focused on virulence had limited resolution, because of the lack of clear gene-for-gene interactions in the wheat/P. nodorum pathosystem (6). The ability to resolve discrete genotypes was increased by using restriction fragment length polymorphisms (RFLPs) (22). RFLP markers are especially well suited for studies that focus on the role of selectively neutral evolutionary processes such as mating system, genetic drift, and gene flow.

Long distance gene flow is a potential threat to the successful use of resistance genes in local disease management programs. New epidemics can be started by a few immigrants already adapted to resistance genes present in other countries or continents, e.g., rust isolates in Australia (5). Behind an epidemic front, recombination may incorporate new alleles into resident populations through sexual reproduction (3). McDonald et al. (10) assayed the genetic structure of $P$. nodorum within a Texas field population using nuclear RFLP markers. The population was characterized by high gene and genotype diversity, and alleles at

Corresponding author: B. A. McDonald; E-mail address: b-mcdonald@tamu.edu

Publication no. P-1997-0207-01R

(C) 1997 The American Phytopathological Society different loci were in gametic equilibrium. This provided evidence for the regular occurrence of sexual reproduction in populations of $P$. nodorum in Texas, although perithecia have been difficult to identify in the field. Because of the high degree of genotype diversity found within populations and the limited number of isolates that can be assayed with current molecular techniques, direct estimates of gene flow through detection of identical genotypes are not likely to be practical in $P$. nodorum. However, gene flow can be estimated indirectly based on the distribution of alleles at RFLP loci in different populations $(9,27)$.

The objectives of this experiment were to (i) characterize the amount and distribution of genetic variation within and among populations of $P$. nodorum from Europe and the United States and (ii) use this information to infer the role of different evolutionary forces on the population genetics of $P$. nodorum.

\section{MATERIALS AND METHODS}

Hierarchical collection of isolates. Hierarchical sampling strategies were used to investigate genetic structure at different spatial scales within each population. All fields were infected naturally. The sampling strategy used for the population from Overton, TX, was described previously (10). The 68 Texas isolates originated from 65 lesions on 27 leaves collected from eight sites separated by $10 \mathrm{~m}$ within a single field in 1992 . The 77 isolates of $P$. nodorum from Oregon originated from infected flag leaves and heads collected at the end of the growing season in 1993 from three sites in a field in Hyslop. Sites were separated by at least $10 \mathrm{~m}$. The 43 leaf isolates were taken from 43 lesions on 18 leaves. Ten of these 43 isolates were taken from different lesions on a single leaf. The 34 head isolates were sampled from 34 kernels on 17 heads. In Zurich, Switzerland, collections of infected flag or F-1 leaves were made at 10-m intervals along each 
of two parallel 50-m transects from a commercial field at the end of the 1994 growing season. One isolate was taken from each of five infected leaves from each of 10 sites in the field, giving 50 Swiss isolates. In total, 195 isolates were analyzed in this experiment.

RFLP analysis. DNA extractions from lyophilized fungal cultures, Southern blotting, and hybridizations were carried out as described previously (10). All fungal DNA were digested with EcoRI. Seven anonymous probes (Table 1) that hybridized to individual loci were used to obtain RFLP allele frequency data for each RFLP locus (10). An anonymous probe (pSNS4) that hybridized to a dispersed repetitive element was used as a DNA fingerprint to detect clones and measure genotype diversity (10).

Data analysis. The different restriction fragment size variants detected by each probe were treated as alleles at individual RFLP loci. Allele frequencies were calculated for individual RFLP loci for all populations. In the Texas and Oregon populations, DNA fingerprints detected several clones, often originating from different lesions on the same leaf or head. At least two isolates, on average, were sampled from each leaf or head in these populations. The result was that the degree of clonality in the Texas and Oregon populations was likely overrepresented relative to the Swiss population, in which only one isolate was taken from each leaf. To correct for the effect of sampling the same clone from a leaf sev- eral times in these populations, gametic disequilibrium was measured among individual RFLP loci using only a single representative of each genotype. This subsample of isolates was called a "clone-corrected" sample. The purpose of using a clone-corrected sample was to eliminate artifactual associations among loci that result from sampling the same clone many times and, thus, correct the bias introduced by the different sampling methods used in these populations.

Genetic variation within populations. Nei's measure of gene diversity $\left(\mathrm{H}_{i}\right)(14)$ was calculated for each population. $\mathrm{H}_{i}$ is the probability that two random draws from population $i$ yield different alleles at one locus. Genotype diversity in each population was estimated with Stoddart and Taylor's measure (24) as described previously (10). The resolution of DNA fingerprints based on hybridization to pSNS4 was conservatively estimated using the method described by Jeffreys et al. (8). Two sets of 24 isolates were used for this analysis. One set (S1) was part of the Swiss population considered in this paper, where as the second set (S2) of isolates came from a different Swiss field population sampled in the same year. Each set of 24 isolates was present on one gel and only fragments $<14 \mathrm{~kb}$ in size were scored. The frequencies of individual DNA fragments and the average number of fragments $<14 \mathrm{~kb}$ in size per isolate were determined for each set of DNA fingerprints. The probability of sharing the same DNA profile by chance

TABLE 1. Clone-corrected allele frequencies and Nei's measures of gene diversity for seven restriction fragment length polymorphism loci in field populations of Phaeosphaeria nodorum from Switzerland (CH-T2), Texas (TX-92), and Oregon (OR-93)

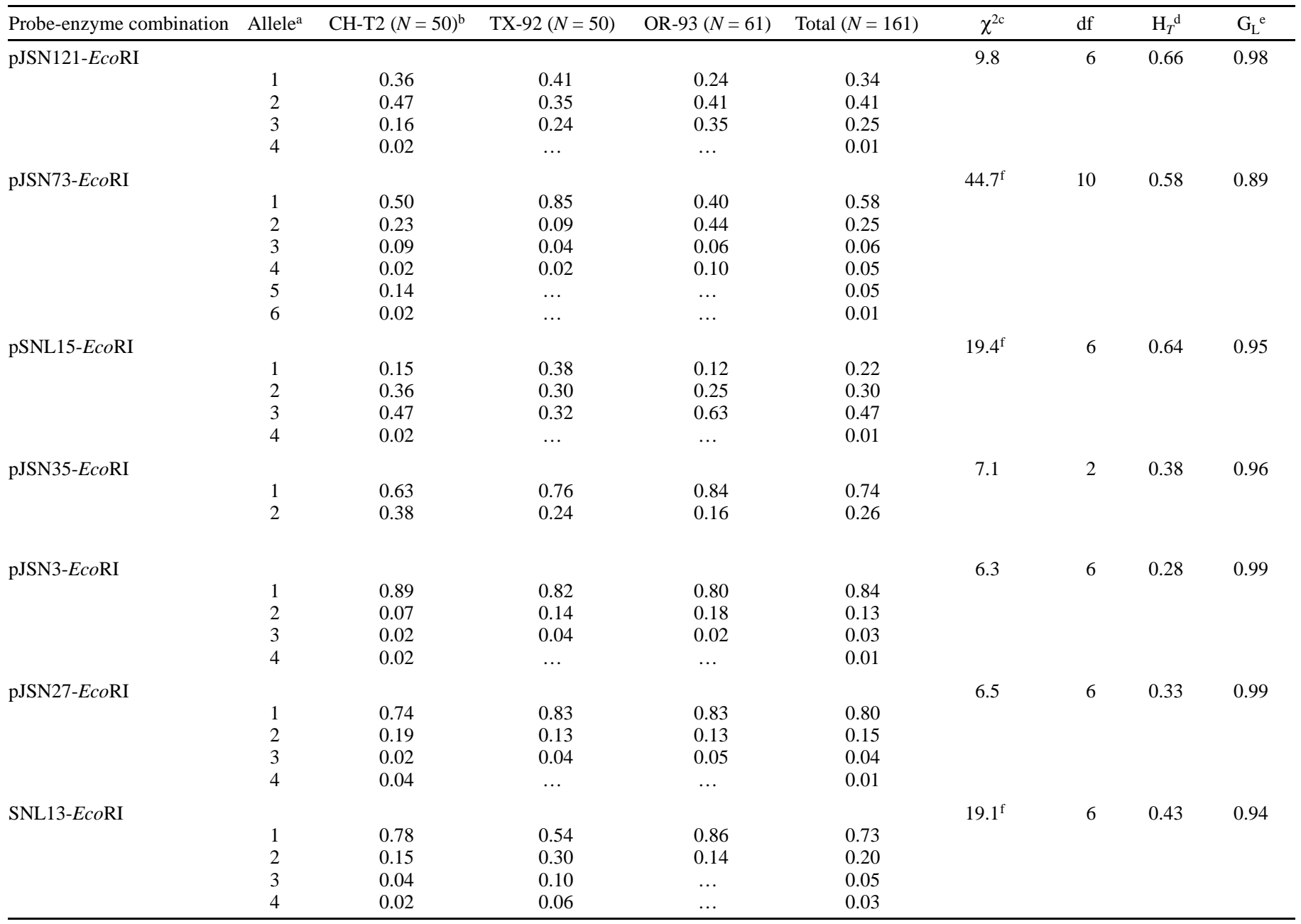

a Allele designation according to the order of McDonald et al. (11).

${ }^{\mathrm{b}} \mathrm{N}$ is the number of single spore isolates.

${ }^{\mathrm{c}}$ Contingency chi-square test for heterogeneity of allele frequencies among field populations.

${ }^{\mathrm{d}}$ Nei's measure of gene diversity across the three populations.

${ }^{e} \mathrm{G}_{\mathrm{L}}$ is the proportion of gene diversity found within field populations.

${ }^{\mathrm{f}} P<0.005$. 
was then estimated as $q^{n}$, in which $q$ was the mean frequency of individual DNA fragments for each population and $n$ was the average number of DNA fragments per isolate for each population (8).

If allele frequencies were distributed evenly at each locus and each locus was independent, then we would expect to find multilocus haplotypes at equal frequencies in a random mating population. In this case, the ability of multilocus haplotypes to differentiate individuals can be estimated based on the possible number of multilocus haplotypes in a population.

Since allele frequencies usually exhibit an uneven distribution for each locus, the probability that two randomly chosen isolates will share the same multilocus haplotype is

$$
P=\prod_{l-1}^{n} \mathrm{Ji}_{l}
$$

in which Ji is Nei's measure of genetic identity (14) for each of $l$ loci.

To directly compare the resolution of DNA fingerprints versus multilocus haplotypes for differentiating genotypes, a most common haplotype was constructed: on one hand, based on allele frequency data at individual RFLP loci and, on the other hand, based on the DNA fingerprint data (pSNS4) in each set of 24 isolates used for the quantitative analysis of the DNA fingerprint. With uneven allele frequency distributions, the probability that two randomly chosen isolates will share the same multilocus haplotype is closer to the square of the expected frequency of the most common multilocus haplotype, which is the squared product of the frequency of the most common allele $c$ at each of $n$ loci.

$$
P \approx \frac{1}{\left(\prod_{l=1}^{n} c_{l}\right)^{2}}
$$

Pairs of RFLP loci were tested for departures from gametic equilibrium as suggested by Weir (25). Disequilibrium between two loci was measured by the disequilibrium coefficient (D) for two alleles at different loci. D was calculated as the observed frequency of a particular gamete minus the expected frequency of the gamete. Tests for significance were as described previously (10).

Comparisons between populations. Differences in allele frequencies between populations were tested using contingency $\chi^{2}$ tests (26). Nei's measures of genetic identity and distance were used to measure genetic similarity between populations (13). In cases in which variable rates of gene substitution occur among loci and identities are large at individual loci, Nei (13) proposed a more appropriate measure of genetic distance given by

$$
\mathrm{D}^{\prime}=\frac{\sum_{j=1}^{n} d j}{n}
$$

in which $d j$ is the value of $-\ln \mathrm{I}_{j}(\mathrm{I}=$ genetic identity) at the $j$ th locus and $n$ is the number of loci examined. In this case, $\mathrm{D}^{\prime}$ is based on the geometric mean of the gene identities instead of the arithmetic mean.

The amount of gene flow between populations was quantified by using population differentiation $\left(\mathrm{G}_{\mathrm{ST}}\right)$ to estimate the average

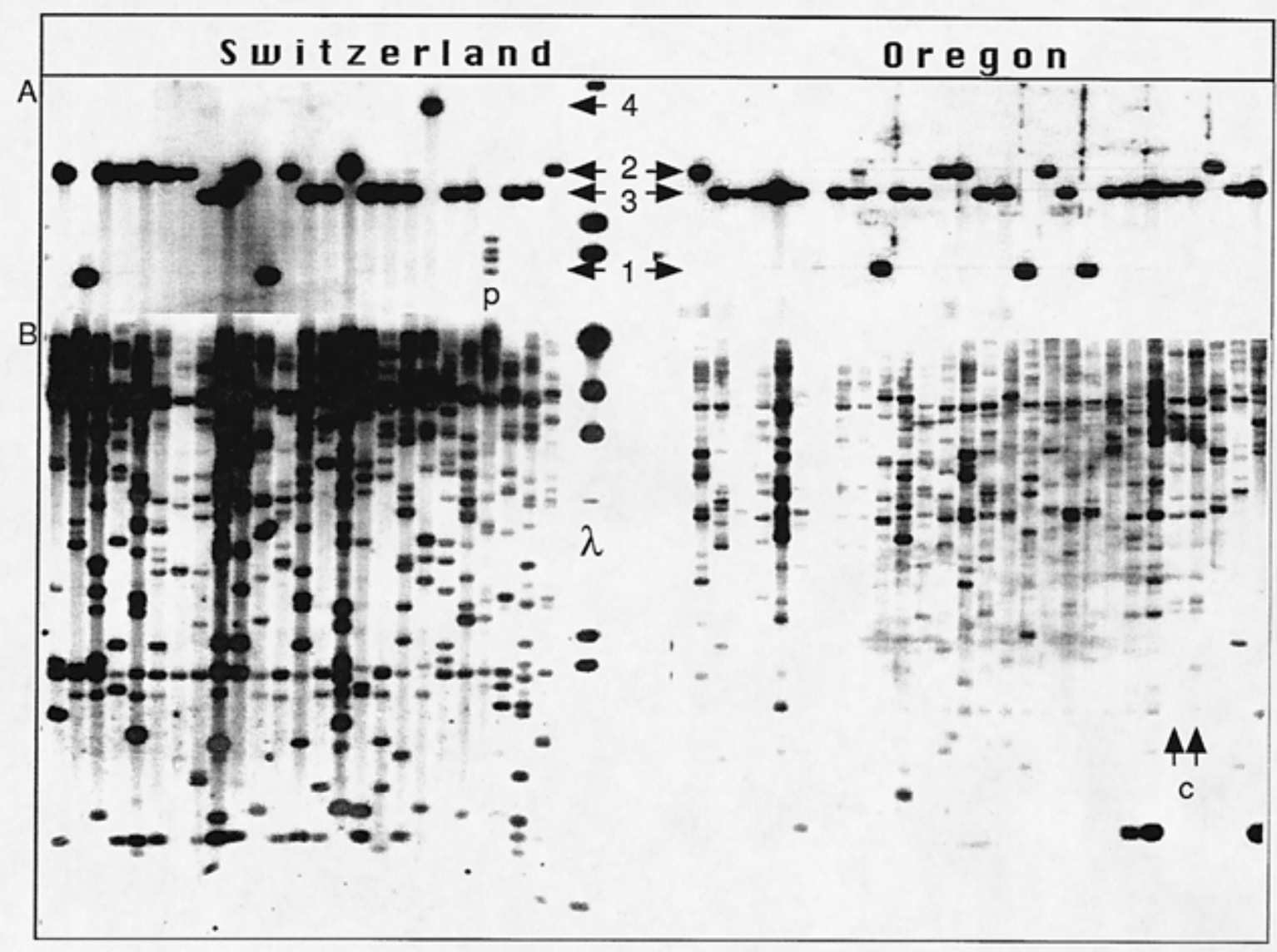

Fig. 1. Sharing of restriction fragment length polymorphism (RFLP) alleles and similarity of DNA fingerprints between Oregon and Swiss populations of Phaeosphaeria nodorum. A, Probe pSNL15 hybridized to DNA digested with EcoRI. Shared RFLP alleles are indicated with arrows. Alleles 1, 2, and 3 were detected in the Swiss and the Oregon populations. The private allele 4 was only found in the Swiss population. The letter p indicates a partial digestion for this isolate, which had allele 1 at this locus. B, DNA fingerprints based on hybridization of probe pSNS4 to the same P. nodorum isolates shown in A. Vertical arrows (c) indicate clones in the Oregon population. All DNA fingerprints in the Swiss population were different. 
number of migrants $(\mathrm{Nm})$ that would need to be exchanged across populations each generation to maintain the observed level of $\mathrm{G}_{\mathrm{ST}}$ as described previously (2).

\section{RESULTS}

In total, 28 alleles were found at the seven RFLP loci. The number of alleles per locus ranged from two to six. All alleles found previously in the Texas population (10) were in the population from Switzerland (Fig. 1 and Table 1). Six new alleles were detected at low frequencies in the Swiss population. Two alleles found in Texas were not detected in the Oregon population. Clone-corrected allele frequencies and measures of gene diversity for each population are shown in Table 1 . Gene diversities within each field were high, averaging 0.47 across the seven RFLP loci. Three out of seven loci showed significant differences in allele frequencies between populations (Table 1).

DNA fingerprints based on hybridization with probe pSNS4 are shown in Figure 1. A total of 60 fragments were scored in both sets (S1 and S2) of 24 Swiss isolates. On average, 14.4 fragments per isolate were scored in set S1, and 14.1 fragments were scored in the second set (S2). Average fragment frequencies were 0.239 and 0.252 in S1 and S2, respectively. For probe pSNS4, the probability of shared DNA fingerprints by chance was estimated as 2.4 $\times 10^{-9}$, on average, for the two sets used for the quantitative analysis of the DNA fingerprint. The expected frequency of the theoretical most common DNA fingerprint was $3.0 \times 10^{-7}$. DNA fingerprints had greater resolution to distinguish genotypes than multilocus haplotypes. In the Swiss population, four pairs of isolates having identical multilocus haplotypes were differentiated by the DNA fingerprint probe pSNS4. This finding was also reflected by the higher probability of shared multilocus haplotypes $(8.1 \times$ $10^{-5}$ by equation 1) compared with DNA fingerprints and the higher expected frequency of the most common multilocus haplotype $\left(4.1 \times 10^{-2}\right.$ by equation 2$)$. The probability that two randomly chosen isolates would share the same multilocus haplotype by

TABLE 2. Nei's measure of gene identity (I) and the gene flow parameter (Nm) between Swiss (CH-T2), Texas (TX-92), and Oregon (OR-93) populations and across populations of Phaeosphaeria nodorum

\begin{tabular}{|c|c|c|c|c|c|c|}
\hline \multirow{2}{*}{$\begin{array}{l}\text { Probe-enzyme } \\
\text { combination }\end{array}$} & \multicolumn{2}{|c|}{ I } & \multicolumn{2}{|c|}{$\mathrm{Nm}$} & \multirow[b]{2}{*}{ Total Nm } & \multirow[b]{2}{*}{$\mathrm{G}_{\mathrm{ST}^{\mathrm{a}}}{ }^{\mathrm{a}}$} \\
\hline & TX-92 & OR-93 & TX-92 & $\overline{\text { OR-93 }}$ & & \\
\hline pJSN121-EcoRI & & & & & 23 & 0.02 \\
\hline $\mathrm{CH}-\mathrm{T} 2$ & 0.97 & 0.92 & 51 & 23 & & \\
\hline TX-92 & $\ldots$ & 0.93 & $\ldots$ & 28 & & \\
\hline pJSN73-EcoRI & & & & & 4 & 0.11 \\
\hline $\mathrm{CH}-\mathrm{T} 2$ & 0.91 & 0.89 & 6 & 16 & & \\
\hline TX-92 & $\ldots$ & 0.74 & $\ldots$ & 4 & & \\
\hline pSNL15-EcoRI & & & & & 10 & 0.05 \\
\hline $\mathrm{CH}-\mathrm{T} 2$ & 0.89 & 0.96 & 16 & 28 & & \\
\hline TX-92 & $\ldots$ & 0.80 & $\ldots$ & 7 & & \\
\hline pJSN35-EcoRI & & & & & 11 & 0.04 \\
\hline $\mathrm{CH}-\mathrm{T} 2$ & 0.97 & 0.94 & 23 & 8 & & \\
\hline TX-92 & $\ldots$ & 0.99 & $\ldots$ & 46 & & \\
\hline pJSN3-EcoRI & & & & & 33 & 0.02 \\
\hline CH-T2 & 0.99 & 0.99 & 44 & 23 & & \\
\hline TX-92 & $\ldots$ & 0.99 & $\ldots$ & 211 & & \\
\hline pJSN27-EcoRI & & & & & 54 & 0.01 \\
\hline $\mathrm{CH}-\mathrm{T} 2$ & 0.99 & 0.99 & 48 & 54 & & \\
\hline TX-92 & $\ldots$ & 1.00 & $\ldots$ & 5750 & & \\
\hline pSNL13-EcoRI & & & & & 8 & 0.06 \\
\hline $\mathrm{CH}-\mathrm{T} 2$ & 0.94 & 0.99 & 11 & 68 & & \\
\hline TX-92 & $\ldots$ & 0.92 & $\ldots$ & 6 & & \\
\hline
\end{tabular}

a Population differentiation. chance was estimated (by equation 1 based on Nei's Ji) as 0.01 for the Swiss and Texas populations and 0.02 for the Oregon population.

Genotypic diversity based on DNA fingerprints was at $100 \%$ of its theoretical maximum in the Swiss population, i.e., every isolate had a unique fingerprint. Genotype diversity was lower in the Oregon ( $\hat{G}=69 \%$ of maximum value) and Texas ( $\hat{G}=42 \%$ of maximum value) populations, in which sampling of several lesions per leaf or head increased the proportion of clones. In the Oregon population, nine genotypes were found more than once. Eight of these nine clones originated from different lesions on the same leaf or from different kernels on the same head. One of the clones was found twice on different heads at the same site in the field. The most common clone was found four times in an assay of 10 isolates from different lesions on the same leaf. The other six isolates from this leaf all had different genotypes. No shared DNA fingerprints were detected across the populations.

On average, $96 \%$ of the gene diversity in the three populations was distributed within populations (Table 1). According to Nei's measures of genetic identity (I) and population differentiation $\left(\mathrm{G}_{\mathrm{ST}}\right)$, the differences between pairs of populations were small across all RFLP loci (Table 2). The average $\mathrm{G}_{\mathrm{ST}}$ across loci was 0.04 . This value was used to calculate $\mathrm{Nm}$, the average number of migrants that would need to be exchanged across populations each generation to maintain the observed level of $\mathrm{G}_{\mathrm{ST}} . \mathrm{Nm}=11$, on average, across the three populations. Measures of genetic identity averaged across all loci suggested that the Oregon and Texas populations were more similar to the Swiss population than they were to each other (Table 3).

Allele-by-allele comparisons were made for the Swiss and Oregon clone-corrected data sets. The results were similar to the Texas population, as summarized in McDonald et al. (10) (Table 4). A total of 21 overall locus-by-locus comparisons were made in each population. The Swiss population showed one comparison (pJSN121/pJSN3) with significant departure $(P<0.01)$ from equilibrium. This high level of significance was due to one isolate that had rare alleles for both loci. The two departures from equilibrium $(P<0.05)$ in the Oregon population did not involve rare alleles.

\section{DISCUSSION}

The genetic structure of populations of $P$. nodorum. Our results show that field populations of $P$. nodorum exhibit high degrees of gene and genotype diversity distributed on very small spatial scales. In one case, seven different genotypes were collected from a single leaf. On average, over $95 \%$ of the gene diversity was distributed on a local level, i.e., within fields. Although allele frequencies differed significantly for three of the seven RFLP loci, there was a high degree of genetic similarity among three populations separated by large geographical distances. The low $\mathrm{G}_{\mathrm{ST}}$ value indicated little evidence for geographical subdivision among the three populations. All populations exhibited a high degree of genotype diversity and no evidence for clonal lineages,

TABLE 3. Pairwise comparisons of Nei's measures of genetic distance (D) and $\mathrm{D}^{\prime}$ (corrected for large genetic identities) among Swiss (CH-T2), Texas (TX-92), and Oregon (OR-93) populations of Phaeosphaeria nodorum ${ }^{\text {a }}$

\begin{tabular}{lccccccc}
\hline & \multicolumn{3}{c}{ Measures across all loci } & & \multicolumn{2}{c}{$\begin{array}{c}\text { Measures across loci pJSN73, } \\
\text { pSNL13, and pSNL15 }\end{array}$} \\
\cline { 2 - 3 } \cline { 5 - 7 } & TX-92 & OR-93 & & TX-92 & OR-93 & TX-92 & OR-93 \\
\hline CH-T2 & 0.06 & 0.04 & & 0.05 & 0.05 & 0.09 & 0.05 \\
TX-92 & $\ldots$ & 0.09 & $\ldots$ & 0.10 & $\ldots$ & 0.19 \\
\hline
\end{tabular}

a Nei's measures are also shown based on the three loci that showed significant differences in allele frequencies among populations. 
the results being consistent with the hypothesis of random mating. The distribution of genotypes at the end of the growing season combined with the finding of gametic equilibrium to provide evidence for a significant degree of sexual reproduction in the examined populations.

Evidence for gene flow. Gene flow is one of the evolutionary forces that can have a significant impact on the genetic structure of a population. In the absence of gene flow, genetic drift will cause isolated populations to develop different allele frequencies at neutral loci, leading to population differentiation. The high genetic similarity among populations of $P$. nodorum suggests that gene flow occurred across long distances. Since none of isolates shared DNA fingerprints among populations, there was no direct evidence for gene flow. However, the shared alleles at neutral loci could be used to make an indirect measure of gene flow.

The average $\mathrm{G}_{\mathrm{ST}}$ of 0.04 indicated little genetic differentiation among the three populations. The genetic distances were very small considering that the geographic distances between populations ranged from $\sim 2,000$ to $7,000 \mathrm{~km}$. If we assume that the high degree of similarity is due exclusively to gene flow and that the populations are at equilibrium, we can use $\mathrm{G}_{\mathrm{ST}}$ to estimate $\mathrm{Nm}$, the average number of migrants that would need to be exchanged among populations each generation to account for their present lack of subdivision. Nm averaged 11 across all loci and populations, suggesting a level of gene flow that was 11 times greater than needed to prevent populations from diverging by genetic drift.

Indirect estimates of gene flow do not take into account the possibility of periodic, large scale migration events. It is possible that gene flow is not presently occurring between North American and European populations, rather the present lack of subdivision reflects the history of agriculture in North America. If the North American $P$. nodorum population on wheat originated from infected seed brought by European immigrants (20) and later by the U.S. Department of Agriculture (17,23), the North American population may not yet differ significantly from the European population. Since the introduction of wheat to North America is relatively recent (200 to 500 years ago), differentiation through genetic drift would only be expected among populations with small effective population size and limited dispersal potential (28). Under this scenario, the founding population in North America was very large, and there has not been sufficient time for genetic drift to cause significant population subdivision to develop.
Evidence for sexual reproduction. Another factor that appears to have a significant impact on the genetic structure of $P$. nodorum populations is the mating system. It has been known for some time that the sexual stage of $P$. nodorum occurs in nature and that ascospores may be a source of primary inoculum (15). However, it has not been clear whether ascospores make a substantial contribution to the epidemic spread of the fungus or whether the sexual stage plays a major role in its population biology. Our data suggest that the sexual stage plays a significant role in the population biology of this fungus, and it may play an important role in the epidemiology of the disease. Our evidence for sexual reproduction consists of a high degree of genotypic diversity based on DNA fingerprints, a large number of multilocus haplotypes based on seven RFLP loci, and the finding that pairs of alleles at RFLP loci were at gametic equilibrium in each population. We found no evidence for clonal lineages in any population.

The finding of gametic equilibrium among neutral loci does not by itself prove that sexual recombination occurs regularly. The sample sizes per population were too small in this experiment for a statistically powerful test of gametic equilibrium between all but the most common allele pairs. The finding of gametic equilibrium is more significant when considered together with the lack of clones that are distributed over spatial scales exceeding $10 \mathrm{~m}$ and the prior knowledge that ascospores may be a source of primary inoculum (19). Our findings provide new evidence that the sexual stage plays an important role in agricultural populations of $P$. nodorum.

What is the source of primary inoculum for $P$. nodorum? Shah et al. (22) described four potential sources of primary inoculum for $P$. nodorum, three that were asexual (pycnidiospores from infected wheat debris or alternative hosts and infected seeds) and one that was sexual (ascospores from infected wheat debris). Their experiment showed that $P$. nodorum isolates that originated from infected seed could persist to infect leaves and seeds. However, it is not clear whether their experiment was representative of the principal source of inoculum in fields that are infected naturally. Their infected seed came from spikes that had been inoculated with two $P$. nodorum strains at the rate of $10^{6}$ spores $/ \mathrm{ml}$. This rate probably overwhelmed any natural infection that was present.

While Shah et al. (22) showed that infected seed can lead to persistence of genotypes over time, we consider it unlikely that infected seed can explain the distribution and diversity of genotypes found at the end of the growing season in natural field

TABLE 4. Measures of gametic disequilibrium among pairs of restriction fragment length polymorphism (RFLP) loci in Swiss and Oregon populations of Phaeosphaeria nodorum

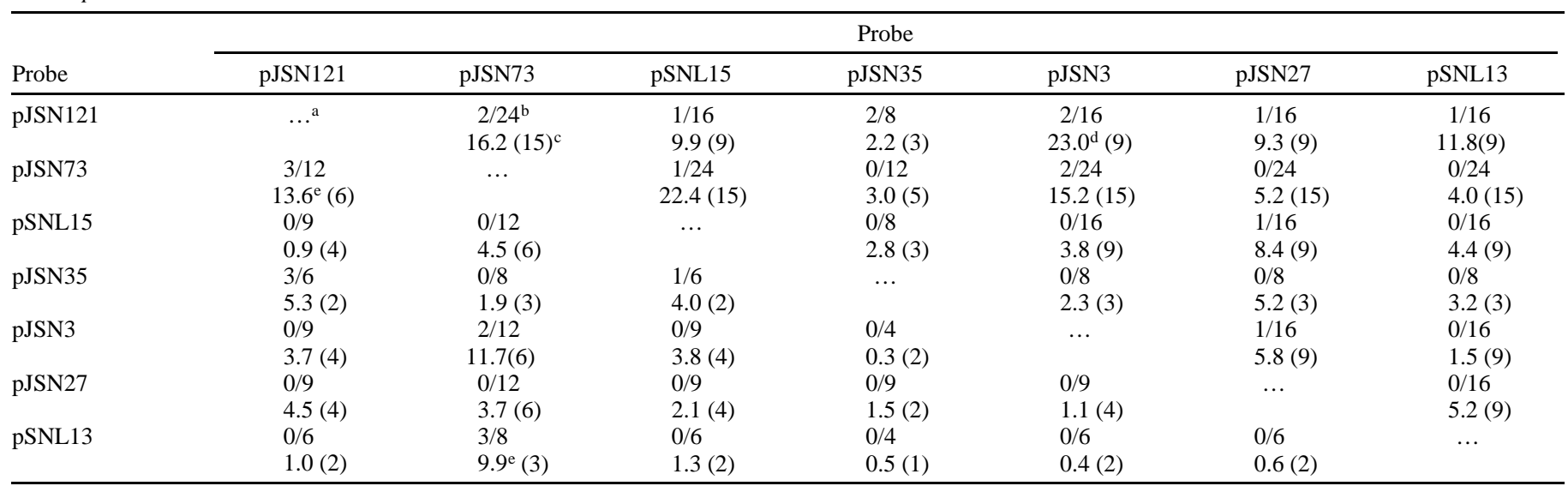

a Numbers above the diagonal are the measures of gametic disequilibrium in the Swiss population. Numbers below are measures for the Oregon population.

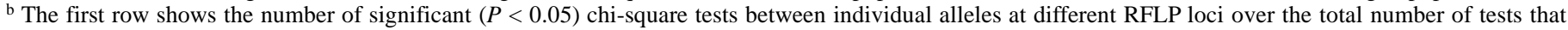
were made.

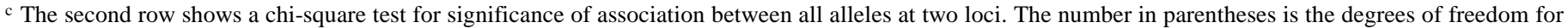
this test.

d $P<0.01$.

e $P<0.05$. 
populations. If the main source of primary inoculum was asexual and from seeds, we would expect to find some clones that were distributed among different locations in a field. Over time, genetic drift and selection would limit the number of genotypes present in field populations, unless sexual reproduction generated new genotypes and wind dispersal distributed ascospores among populations every year. In support of the hypothesis of Shah et al. (22), we found five examples of clones that were distributed among different locations in a field midway through the growing season in the Texas population (10). In the Oregon and Swiss populations, however, we did not find any clones that were shared among different locations within the field. These fields were sampled at the end of the growing season. In eight other populations sampled in Switzerland (50 isolates per population, 400 isolates total), the same pattern emerged. In total, six pairs of clones were found among the 400 isolates, and clone pairs always originated from the same site in the field (S. M. Keller, unpublished data). These findings are not consistent with the hypothesis that the majority of primary inoculum is asexual and seedborne (22).

Since pycnidiospores are so restricted in movement (4), the scale of sampling can have a major impact on the interpretation of our results. Hierarchical sampling on a very small scale is needed to resolve the actual distribution of genotypes in a field. On the finest spatial scale we tested (lesions from the same leaf), it was common to find the same genotype. This probably reflects autoinfection by pycnidiospores. When the scale of sampling was increased to locations separated by $10 \mathrm{~m}$ in a field, the same genotype was found in different locations only in the Texas population, suggesting that pycnidiospores were not dispersed across long distances over the course of the epidemic cycle in the Oregon and Swiss populations. It appears likely that sampling on an intermediate scale $(25$ to $50 \mathrm{~cm})$ is needed to resolve the actual distribution of clones in a field. Our sampling strategy for these three fields was not adequate to accurately delimit the spread of particular clones.

Earlier studies revealed that ascospores can germinate and infect when temperatures are lower than $5^{\circ} \mathrm{C}$, while pycnidiospores require temperatures above $5^{\circ} \mathrm{C}$ to infect leaves (16). This suggests that young wheat plants are more likely to be infected by ascospores in late fall and early spring, in synchrony with the ascospore showers that have been detected at this time of year (12). The spore trapping data, combined with our findings, suggest that ascospores are a major part of the primary inoculum. We believe that pycnidiospores are likely to play an important role in epidemiology on small spatial scales (1 to $2 \mathrm{~m}$ ), but ascospores probably play a more important role in the population biology and perhaps in the epidemiology of disease on a regional scale (tens to hundreds of kilometers; S. M. Keller, unpublished data).

In Switzerland, populations of $P$. nodorum exhibit moderate levels of virulence, and new resistance genes tend to provide protection over many years (M. Winzeler, personal communication). Although variation in pathogenicity was thought to indicate the potential for local adaptation, this was never confirmed by field experiments. Sexual reproduction could explain the high genotype variation in populations of $P$. nodorum. It may also explain why field populations are so similar on a regional scale. Ascosporemediated gene flow among fields separated by tens or hundreds of kilometers would unify populations on a regional basis into a large metapopulation.

\section{ACKNOWLEDGMENTS}

We thank C. Mundt and M. Hoffer for providing infected wheat leaves and heads from Oregon. This work was supported by the Texas Agricultural Experiment Station (Hatch project 6928), the National Science Foundation (grant DEB-9306377), the USDA National Research Initiative Competitive Grants Program (grant 93-37303-9039), and the Swiss National Fund (grant 5002-38966).

\section{LITERATURE CITED}

1. Allingham, E. A., and Jackson, L. F. 1981. Variation in pathogenicity, virulence, and aggressiveness of Septoria nodorum in Florida. Phytopathology 71:1080-1085.

2. Boeger, J. M., Chen, R. S., and McDonald, B. A. 1993. Gene flow between geographic populations of Mycosphaerella graminicola (anamorph Septoria tritici) detected with restriction fragment length polymorphism markers. Phytopathology 83:1148-1154.

3. Brasier, C. M. 1988. Rapid changes in genetic structure of epidemic populations of Ophiostoma ulmi. Nature (Lond.) 332:538-541.

4. Brennan, R. M., Fitt, B. D. L., Taylor, G. S., and Coulhoun, J. 1985. Dispersal of Septoria nodorum pycnidiospores by simulated rain and wind. Phytopathol. Z. 112:291-297.

5. Burdon, J. J., Marshall, D. R., Luig, N. H., and Gow, D. J. S. 1982. Isozyme studies on the origin and evolution of Puccinia graminis f. sp. tritici in Australia. Aust. J. Biol. Sci. 35:231-238.

6. Fried, P. M., and Meister, E. 1987. Inheritance of leaf and head resistance of winter wheat to Septoria nodorum in a diallel cross. Phytopathology 77:1371-1375.

7. Griffiths, E., and Ao, H. C. 1976. Dispersal of Septoria nodorum spores and spread of glume blotch in the field. Trans. Br. Mycol. Soc. 67:413418.

8. Jeffreys, A. J., Wilson, V., and Thein, S. L. 1985. Individual specific "fingerprints" of human DNA. Nature 316:76-79.

9. McDermott, J. M., and McDonald, B. A. 1993. Gene flow in plant pathosystems. Annu. Rev. Phytopathol. 31:353-373.

10. McDonald, B. A., Miles, J., Nelson, L. R., and Pettway, R. E. 1994. Genetic variability in nuclear DNA in the field populations of Stagonospora nodorum. Phytopathology 84:250-255.

11. McDonald, B. A., Pettway, R. E., Chen, R. S., Boeger, J. M., and Martinez, J. P. 1995. The population genetics of Septoria tritici (teleomorph Mycosphaerella graminicola). Can. J. Bot. 73(suppl.):S292S301.

12. Mittelstädt, A., and Fehrmann, H. 1987. Zum Auftreten der Hauptfruchform von Septoria nodorum in der Bundesrepublik Deutschland. J. Plant Dis. Prot. 94(4):380-385.

13. Nei, M. 1972. Genetic distance between populations. Am. Nat. 106:283292.

14. Nei, M. 1973. Analysis of gene diversity in subdivided populations. Proc. Natl. Acad. Sci. U.S.A. 70:3321-3323.

15. Rapilly, F., Foucault, B., and Lacasedieux, J. 1973. Etudes sur l'inoculum de Septoria nodorum Berk. (Leptosphaeria nodorum Mueller) agent de la Septoriose du blé. I. Les ascospores. Annu. Phytopathol. 5:131-141.

16. Rapilly, F., and Skajennikoff, M. 1974. Etudes sur l'inoculum de Septoria nodorum Berk. (Leptosphaeria nodorum Mueller) agent de la Septoriose du blé. II. Les pycnidiospores. Annu. Phytopathol. 6:71-82.

17. Reitz, U. 1976. Wheat in the United States. U.S. Dep. Agric. Agric. Info. Bull. 386.

18. Rufty, R. C., Hebert, T. T., and Murphy, C. F. 1981. Variation in virulence in isolates of Septoria nodorum. Phytopathology 71:593-596.

19. Sanderson, F. R., and Hampton, J. G. 1978. Role of the perfect states in the epidemiology of the common Septoria diseases of wheat. N.Z. J. Agric. Res. 21:277-281.

20. Sauer, J. D. 1993. Pages 217-222 in: Historical Geography of Crop Plants: A Selected Roster. CRC Press, Boca Raton, FL.

21. Scharen, A. L., Eyal, Z., Huffmann, M. D., and Prescott, J. M. 1985. The distribution and frequency of virulence genes in geographically separated populations of Leptosphaeria nodorum. Phytopathology 75:14631468.

22. Shah, D., Bergstrom, G. C., and Ueng, P. P. 1995. Initiation of Septoria nodorum blotch epidemics in winter wheat by seedborne Stagonospora nodorum. Phytopathology 85:452-457.

23. Smith, T. 1900. Inventory of Foreign Seeds and Plants. U.S. Department of Agriculture, Division of Botany, Section of Seed and Plant Introduction, Washington, DC

24. Stoddart, J. A., and Taylor, J. F. 1988. Genotypic diversity: Estimation and prediction in samples. Genetics 118:705-711.

25. Weir, B. S. 1990. Genetic Data Analysis. Sinauer Associates, Inc., Sunderland, Massachusetts.

26. Workman, P. L., and Niswander, J. D. 1970. Population studies on southwestern Indian tribes. II. Local genetic differentiation in the Papago. Am. J. Hum. Genet. 22:24-49.

27. Wright, S. 1951. The genetical structure of populations. Genetics 16:97159.

28. Wright, S. 1968. Evolution and the Genetics of Populations. University of Chicago Press, Chicago. 